\title{
Organizational Network Evolution and Governance Strategies in Megaprojects
}

\author{
Yujie $\mathrm{Lu}^{1}$, Yongkui $\mathrm{Li}^{2}$, Da Pang ${ }^{2}$, and Yunxia Zhang ${ }^{2}$ \\ ${ }^{1}$ Department of Building, School of Design and Environment, National University of Singapore, Singapore \\ ${ }^{2}$ Department of Construction Management of Real Estate, School of Economics and Management, Tongji \\ University, Shanghai, China
}

\begin{abstract}
The organization is the key factor for megaprojects in which thousands of connections and relations intertwine and influence the project performance. However, organizational evolution in megaprojects has not been fully studied. This study investigates the evolution of the organizational network of a megaproject in China using social network analysis (SNA), and then proposes corresponding governance strategies. The result shows that megaproject organizations evolve towards more connected networks but are differentiated for various investors. For government invested projects, the organizational network is well connected and cooperative, yet unstable and requires strategic long-term governance policies; for private invested projects, the network is stable, but collaboration among participants is low, which indicates a need to establish collaborative governance structures. The result complements the organizational evolution theory for megaprojects and offers effective strategies for governing megaproject organizations. This study also helps practitioners better understand the nature and characteristics of megaproject organizations.
\end{abstract}

Keywords: Megaprojects; Social Network Analysis (SNA); organization management; project governance; case study

Paper Type: Research article

\section{Introduction}

Large-scale city infrastructure construction is a key supporting pillar in a nation's economic and social development. As the scale of the project increases, the complexity of projects becomes more evident than before and brings about new challenges. Especially in the city level or regional level where single projects have been gradually replaced by megaprojects, the complexity expanded exponentially together with various factors, including increasing numbers of organizational stakeholders, various funding sources, and diversified project functions. As a result, megaprojects began displaying end products that did not perform up to standard (Szyliowicz and Goetz, 1995).

Organizational governance plays a key role in the execution of megaprojects (Miller and Hobbs, 2005), and has been regarded as the decisive factor affecting project performance (Li et al., 2015). Governance of megaproject organization is difficult due to multiple reasons, such as the diversification and interaction among project participants, complication of organizational

Copyright: Construction Economics and Building 2015. (C) 2015 Yujie Lu, Yongkui Li, Da Pang and Yunxia Zhang. This is an Open Access article distributed under the terms of the Creative Commons Attribution 4.0 Unported (CC BY 4.0) License (https://creativecommons.org/licenses/by/4.0/), allowing third parties to copy and redistribute the material in any medium or format and to remix, transform, and build upon the material for any purpose, even commercially, provided the original work is properly cited and states its license.

Citation: Lu, Y., Li, Y., Pang, D. and Zhang, Y., 2015. Organisational network evolution and governance strategies in megaprojects, Construction Economics and Building, 15(3), 19-33. DOI: http://dx.doi.org/10.5130/AJCEB.v15i3.4609

Corresponding author: Yongkui Li; Email-y.k.lee@126.com

Publisher: University of Technology Sydney (UTS) ePress 
relationships, personal behaviour dynamics and uncertainty in the long construction period. Improper organization governance leads to poor performance of megaprojects, such as cost overruns, schedule delays, or losing control (Gordon, 2008). It is therefore crucial to establish the effective organizational governance during the entire megaproject process.

To improve the effectiveness of prolonged governing megaproject organizations, this study aims to: 1) analyse dynamic characteristics of megaproject organization evolution and regularity based on Social Network Analysis (SNA) method and a megaproject case study in China; 2) conduct a comparative analysis of dynamic characteristics for two-types of megaproject organizations: government invested and private invested projects; and 3) propose effective governance strategies for different types of megaproject organizations. The result will enrich the current knowledge of megaproject organization governance by analysing the dynamic evolution of megaproject organizations, and provide practical strategies for governing megaproject organizations.

The paper is structured in six sections. The next section reviews pertinent studies, followed by section three that explains the research design, case selection, and data collection. Section four analyses the results of the organizational network, and relevant organizational governance policies are discussed in section five. The last section summarizes this study.

\section{Literature Review}

Organization is the key factor that influences project tasks completion (Chen, 2005) and project performance. An inappropriate organization will magnify the risk of unperformed tasks and induce cascading failure phenomenon, especially in a complex project environment.

Traditional project management research regards construction project organization as a formal and stable relationship (Dubois and Gadde, 2000). Scholars have also defined the project organization as a relationship matrix or a network of relationships (Li et al., 2015), and assume that a project organization is composed of multiple transactions between enterprises. The construction project organization is therefore analyzed via the perspective of project contract mode or organization structure (Buzzell and Gale, 1987; Winch, 1989).

However, the studies above have ignored the sociality, temporality and network interactions in a project organization (Loraine, 1994; Thiry and Deguire, 2007), and simply considered the relationship between the individual attributes by using the individual "atomic" thinking. The organization is a multi-level, multi-attribute and continuously evolving network, and not a network with a static and isolated structure. The numbers and types of organization will change constantly in the process of its evolution. Therefore, organizational network theory replaced the "atomic" thinking with "network" thinking, becoming a new logic analysis and research paradigm that tends toward more relational, contextual and systemic understandings (Borgatti and Foster, 2003).

Research on "network" has grown extensively in the last decade, especially on social network (Borgatti and Halgin, 2011). The interest in network analysis spans all of the social sciences and helps solve research questions for various disciplines, such as physics, epidemiology, and biology. In management research, social networks have been used to understand job performance (Sparrowe et al., 2001), creativity (Burt, 2004), and innovation (Obstfeld, 2005). Besides, network analysis has become a standard diagnostic tool in management consulting (Baker, 2000).

In addition, the organizational network governance is a selective, long-lasting and structured autonomous enterprise collection (Jones, Hesterly and Borgatti, 1997). Network governance is different from the corporate governance since network governance is no longer concerned about the shareholders' rights within a single enterprise or the maximum of specific public benefit. It focuses on the maximum value of the whole network (Jeffrey and Salancik, 1978) instead. Such 
organizational evolution calls for a higher requirement for the network governance which has not yet been fully addressed in current studies. For instance, Provan, Milward and Isett (2002)_ENREF 31 explained the core problem of organization network governance is governance mechanism - including commitment, contract and contract. However, they didn't provide particular solutions for megaproject organizational governance which requires dynamic regimes and must adapt to the emerging context (Miller and Hobbs, 2005). Thus, the need for research on the dynamic organizational governance and strategy is essential for managing megaprojects.

The analysis of the organization network can be performed by various methods such as mathematical statistics, computer simulation, and SNA. Among them, SNA is a widely adapted method for many fields (Chinowsky and Taylor, 2012), and it provides a new perspective and method to research project organization and the organization network (Li et al., 2011; Scott and Carrington, 2011). The origin of SNA can be traced back to the psychological study and anthropological study in the 1930s as a research paradigm (Kilduff and Tsai, 2003). SNA focuses on the study of both the relationship among all stakeholders and the overall structure of the network, including issues such as nodes, edges, network density, centrality, central potential, small group, location, role, and so on. For example, Pryke (2005) used SNA to study the effectiveness of project governance which can be significantly influenced by properly designing contracts, incentives, and information exchange relations. Chinowsky, Diekmann and O'Brien (2009) constructed a SNA model to analyse its impact on the project team performance. These studies show significant advantages in analysing the complex social relations in organization governance (Gray, 2001).

\section{Research Design and Data Processing}

\section{Establishment of SNA model}

In order to analyse the structure of the network, the study needs to identify project participants from organizations or individuals, and their relations. Node, known as the "point", is the smallest unit of the network. In a project organization network, a node could be any project participant or stakeholder associated with this project. This study categorizes all relevant parties into four clusters: owners (investors), contractors, designers, and supervision units.

Link, known as "edge" or "tie", is defined as the connection between two nodes in the network. Link represents a specific or a substantive relationship in reality, with or without direction. In the SNA model of project organization, link represents project-based relationship, which could be the contract, command, coordination, information exchange, or performance incentive relationship.

Since this study aims to investigate the evolution of the megaproject organization, which is based on the contractual and project collaborative relations, SNA network was selected and established as the non-directional and unweighted network. When a relationship exists, the link is 1, otherwise the link is 0 . It is worth mentioning that the network structure only depends on the relationship existing among all the nodes but is irrelevant to individual project information. Indexes, called indicators, are the key to revealing the uniqueness and attributes in a SNA network. Through these indicators, one can not only conduct quantitative analysis for individual parties and connections, but also an overall analysis of an entire network, and therefore provide analytical results at both individual and network levels.

In order to investigate characteristics and regularity of megaproject organization evolution, this study analyses specific attributes of organization network, including the closeness of network, connectivity of network, and position of network nodes. In particular, this study uses six 
parameters to analyse the SNA result, as shown in Table 1. Closeness is measured by the density and clustering coefficient; whereas connectivity is measured by average path length and component; position of network node is measured by degree centrality and closeness centrality. The former four indicators measure the evolution of the overall network, while the latter two measure the evolution of individual nodes. All these indicators have been widely applied to existing studies, as shown in the last column of Table 1.

Table 1: Selected SNA indicators for the analysis of megaproject organizational network

\begin{tabular}{|l|l|l|l|}
\hline \multicolumn{1}{|c|}{ Indicator } & Symbol & \multicolumn{1}{|c|}{ Interpretation and calculations } & \multicolumn{1}{c|}{ Reference } \\
\hline Density & $\Delta$ & $\begin{array}{l}\text { Represent the closeness of a network } \\
\text { Calculated by: the amount of potential connections } \\
\text { between individuals that are actually present }\end{array}$ & $\begin{array}{l}\text { (Jones et al., } \\
\text { 2011) }\end{array}$ \\
\hline $\begin{array}{l}\text { Clustering } \\
\text { Coefficient }\end{array}$ & $\mathrm{C}$ & $\begin{array}{l}\text { An indication of the small world. } \\
\text { Calculated by: the fraction of connected triples in the } \\
\text { graph that are triangle }\end{array}$ & (Newman, 2003) \\
\hline $\begin{array}{l}\text { Average Path } \\
\text { Length }\end{array}$ & $\mathrm{d}$ & $\begin{array}{l}\text { An indicator of the networks interconnectedness } \\
\text { Calculated by: the average length of the shortest paths } \\
\text { between all possible node pairs }\end{array}$ & $\begin{array}{l}\text { (Wasserman, } \\
\text { 1994) }\end{array}$ \\
\hline Component & $\mathrm{CO}$ & $\begin{array}{l}\text { Represent network connectivity degree } \\
\text { Calculated by: a subset of nodes interconnected by edges }\end{array}$ & $\begin{array}{l}\text { (Liu, Han and } \\
\text { Xu, 2014) }\end{array}$ \\
\hline $\begin{array}{l}\text { Degree } \\
\text { Centrality }\end{array}$ & $C_{D}(i)$ & $\begin{array}{l}\text { Represent the level of importance of a particular node in a } \\
\text { network. } \\
\text { Calculated by: a count of the number of ties to other } \\
\text { nodes in the network }\end{array}$ & $\begin{array}{l}\text { (Quinn, Chen } \\
\text { and Mulvenna, } \\
\text { 2012) }\end{array}$ \\
\hline $\begin{array}{l}\text { Closeness } \\
\text { Centrality }\end{array}$ & $C_{C}(i)$ & $\begin{array}{l}\text { Represent the degree of influence or control of a } \\
\text { node by others. } \\
\text { Calculated by: the sum of geodesic distances to all } \\
\text { other nodes }\end{array}$ & $\begin{array}{l}\text { (Quinn, Chen } \\
\text { and Mulvenna, } \\
\text { 2012) }\end{array}$ \\
\hline
\end{tabular}

\section{Case selection}

This study selected a typical case of scientific and technological development park in Wuxi, China. Wuxi is a city located in the southern part of Jiangsu province, China, with a population of 550,000. Wuxi national hi-tech development zone (WNHTDZ) was founded in 1992, and listed as one of the nation's high and new technology zones. Since 2005, WNHTDZ has entered a transition phase which requires massive transformation and infrastructure upgrade, so the demand of construction projects has also increased greatly.

Currently, the total area of WNHTDZ has reached to 220 square kilometres, with total Gross Domestic Products (GDP) of 121.3 billion yuan (note: 1 yuan equals to 0.16 US dollar) in 2013. In the last eight years, the overall capacity of WNHTDZ, including both scale of industry and technological outputs, has been ranked second in Jiangsu province, and ranked first tier among all national development zones. Selecting WNHTDZ as a case can not only provide practical insights to the governance and management of local construction projects, but can potentially contribute to the understanding the governance of construction projects in other development zones.

From 2008 to 2013, a total of 1897 new construction projects were approved in WNHTDZ, including 946 civil engineering projects (50\%), 189 municipal engineering projects (10\%) and 762 industrial projects $(40 \%)$. All projects can be classified into two categories: government invested projects (GIPs) and private invested projects (PIPs). The numbers of both GIPs and PIPs are shown in Table 2. 
To complete these projects, more than 1000 relevant companies were involved in the construction activities. These companies and their relations form a giant organizational network system with complex relationships. In addition, the construction of WNHTDZ is of a long duration and there are many organizational changes happening during the construction period. The combination of vast organizational network and its evolution present a great challenge to governance of the organizational network for WNHTDZ. Therefore, the selection of WNHTDZ as a typical case not only provides critical understanding of such mega scale organization governance, but also offers a generic solution to similar megaprojects in other regional development zones.

Table 2: Numbers of government invested projects (GIPs) and private invested projects (PIPs) from 2008 to 2013

\begin{tabular}{|c|c|c|c|c|c|c|}
\hline & 2008 & 2009 & 2010 & 2011 & 2012 & 2013 \\
\hline GIPs & 53 & 71 & 89 & 63 & 64 & 33 \\
\hline PIPs & 279 & 217 & 345 & 352 & 205 & 126 \\
\hline
\end{tabular}

\section{Data Collection and Processing}

One of the authors worked closely with WNHTDZ and collected second hand data since 2008. The data were extracted from the information system hosted by WNHTDZ administration. A total of 1,897 new construction projects that happened from 2008 to 2013 were selected as data input in SNA model. In order to guarantee the data validity, the study sorted, summarized, filtered, and cleaned the data after collection.

The 1,897 construction projects and their relevant stakeholders have also been summarized. In total, there are 1450 contractors, including 680 owners (investors), 174 designers, 541 contractors, and 55 supervision units. They involved all aspects of construction projects, such as the government regulations, fiscal and financing, planning, construction, environmental protection, and other departments, forming an open and complex organization system. To facilitate the SNA analysis, all associated projects and stakeholders were coded by the rules described in Table 3.

On the basis of the coding, this study established the "two-mode network" (Doreian, Batagelj and Ferligoj, 2004) that represents the relationship between construction projects and participants. The matrix Bij was composed by constructing all participants and projects, where the row represents construction projects, starting with 1, 2, and so on, until 1897 ; the column represents all participants, starting with 1,2 , and so on, until 1450. If $\mathrm{Bij}=1$, then it represents that construction contractors $\mathrm{j}$ has involved in the construction project $\mathrm{i}$, vice versa $\mathrm{Bij}=0$.

As the purpose of this paper is to investigate the network relationship among project organizations, the "two-mode" network needs to be converted into the "one-mode" network (Doreian, Batagelj and Ferligoj, 2004) that represents the relationship among all participants.

Such a conversion can be performed by using the adjacency matrix $\mathrm{A}$, where $A_{i k}=\sum B_{i j} * B_{j i}$. If $\mathrm{A}=\mathrm{n}$, it means that there are $\mathrm{n}$ times of connections between node $\mathrm{i}$ and node $\mathrm{k}$, indicated in a two-way arrow line; if $\mathrm{A}=0$, it represents no connection between node $\mathrm{i}$ and node $\mathrm{k}$. When two participants are involved in a project, they form a relationship and the link is 1 . This is binary network in which the relationship between 0 and 1 is not taken into consideration.

\section{SNA Computation}

The study will consider six-years (2008-2013) of organizational evolution. In each year, the organizational network was computed based on the "2-year" rule, meaning that average 
construction duration in WNHTDZ will last for 2 years. To align with this norm, the network in each year constituted all relevant participants in that particular year and also in the previous year. For instance, when calculating the network for 2012, all companies involved in 2012 and in 2011 were considered in the network. This 2-year rule ensures the continuity and coherence of the SNA model with the construction practice.

In addition, China's high-speed infrastructure growth is based on the "dual-track" economy, where one force is from government investment, another force comes from the market driven competition. In this case, such "dual-track" system will be interpreted as GIPs and PIPs. A comparison between GIPs and PIPs shows significant influences for making future governance policy. Therefore, this study divides all project data into two parts, comparing GIPs to PIPs to find out different evolution rules and strategies. Finally, all calculations were fed in and solved by the SNA professional software, UNCINET6.0, and the result explained in the following section.

Table 3: Participation unit and the coding method for construction projects

\begin{tabular}{|l|l|l|}
\hline Example & \multicolumn{1}{|c|}{ Participants } \\
\hline Company's nature
\end{tabular}




\section{Result and Analysis}

\section{Overall network evolution process}

In last five years, the number of GIPs increased (see Figure 1), the number of links rose, and the collaboration network was greatly strengthened. Meanwhile, companies in the network can be divided into two parts - companies in the primary network (also known as a component that is a maximal set of nodes that are connected) and companies at the edge of the network. The latter part was gradually merged with the former part during the observation period.

The PIPs network showed a high density from the start (see Figure 2), and has grown at a stable rate in five years. One interesting finding is that, between the years 2009 and 2014, although the number of nodes grows by 110 only (increased by 18\%), the number of links almost doubled (increased by 194\%), declaring a high connectivity of the whole network.

Similar to GIPs network, companies at the edge of PIPs network gradually decreased and merged to the primary network as a component. The component (see Figure 3d) for both GIPs and PIPs increased shows that more companies were connected to the primary network, and fewer companies isolated. Such expanded primary network enables more collaboration among companies.

Apart from the above, both the GIP and PIP networks belong to sparse network, with the network density of around 0.03 and 0.01 respectively, indicating low network collaboration. A possible explanation is due to the project tendering system, where the collaborative partners are selected by owners rather than by free selection, imposing restrictions on the emergence of largescale collaborative alliance.

\section{Comparative Analysis between GIPs and PIPs: Whole Network}

The comparison between GIPs and PIPs' network is illustrated in Figure 3, and discussed as follows. GIPs have higher network density (0.03 vs. 0.01$)$ and clustering coefficient (0.4 vs. 0.2) than PIPs (see Figure $3 \mathrm{a}$ and Figure 3b), indicating that GIPs have closer collaboration and high possibility of small clusters. The reason could be explained as follows. For GIPs, they are mainly affected by the government investment system, where one (government) owner typically corresponds to many projects, forming a more owner-centralized network. However, for PIPs, one (private) normally deals with one project at a time, constructing a one-to-one network.

The collaborative degree of PIPs is relatively stable while the GIPs fluctuates over time (see Figure $3 \mathrm{~b}$ and Figure $3 \mathrm{~b}$ ). This is mainly because PIPs are primarily oriented by the market mechanism which is relatively stable. However, the collaboration of GIPs was influenced by many government administrative interferences, such as new policies, rules and regulations, economic incentive plans, and so on. For instance, GIPs showed leadership in pioneering innovations, such as use of the new technology of Building Information Modelling (BIM) in buildings, and explored innovative project financing mechanisms, such as Public Private Partnership (PPP). Taking new initiatives will bring additional inputs to the network and may change the collaboration structure.

The node distance of PIPs decreased sharply from 4.4 to 3.5 (see Figure 3c), indicating that the relationship between any two parties in the network is getting closer and the potential collaboration among companies is easier than ever, while the distance for GIPs was kept at a low level since 2009, and the trend only decreased slightly. In addition, the differences between the two types of project (GIPs and PIPs) have narrowed in the last five years. In 2009, a large gap existed for the average distance of the two types of network, with PIPs of 4.4 and GIPs of 3.4, respectively. But in 2013, the average distance of these two networks became quite similar, with PIPs of 3.5 and GIPs of 3.3 respectively. This indicates that, in the long term, the behaviour of different types of projects may tend towards "norm". 


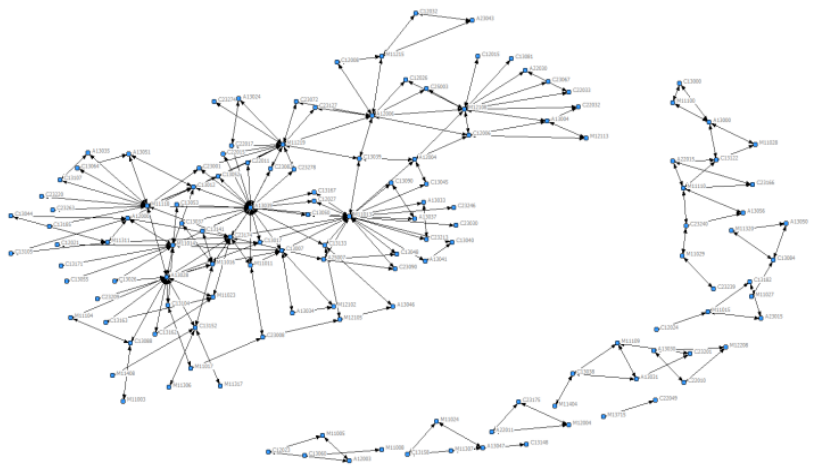

2009 (137 nodes and 568 connections)

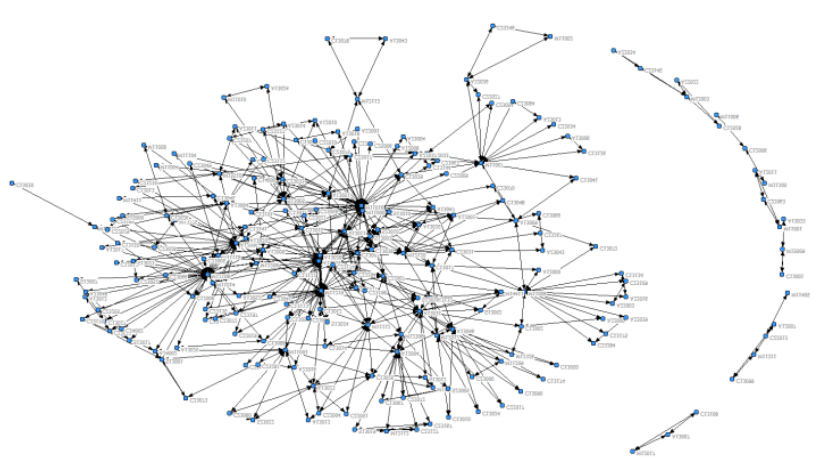

2012 (212 nodes and 1208 connections)

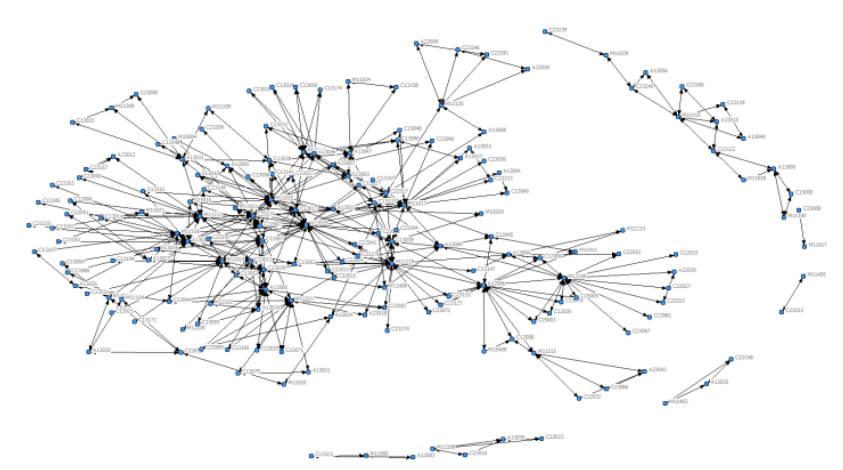

2010 (178 nodes and 1033 connections)

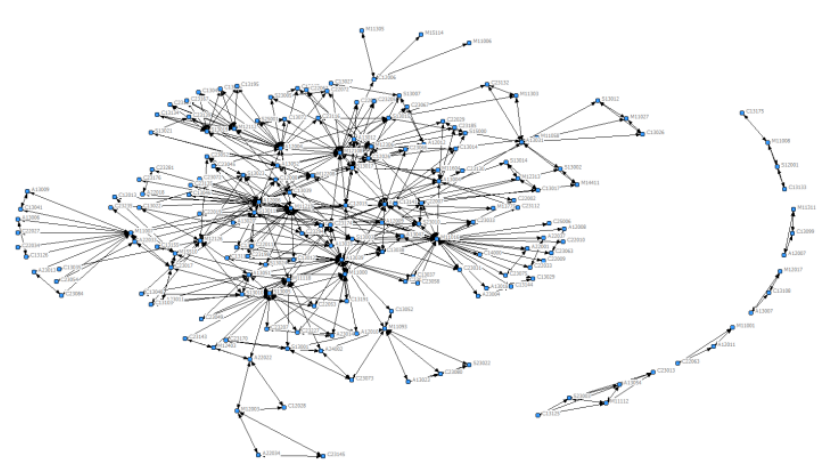

2013 (183 nodes and 1112 connections)

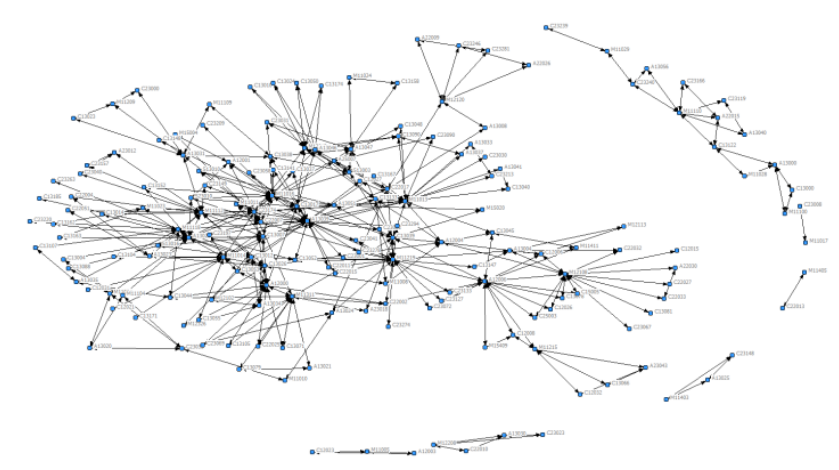

2011 (201 nodes and 1166 connections)

Figure 1: Organizational evolution of GIPs in WNHTDZ 


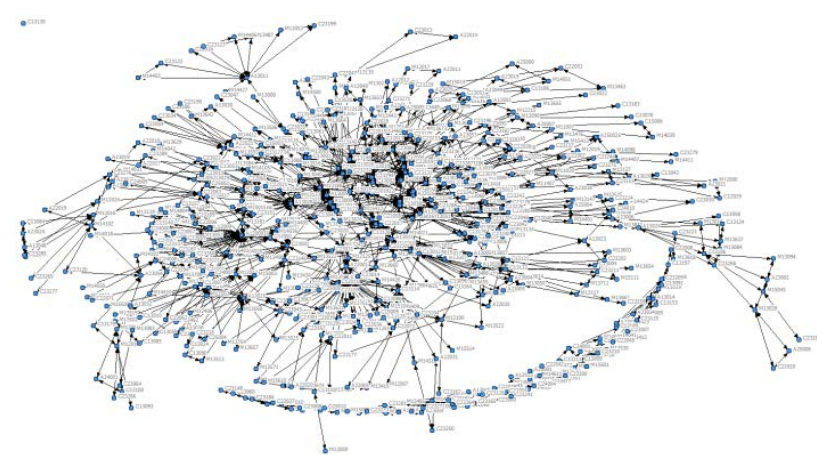

2009 (604 nodes and 2367 connections)

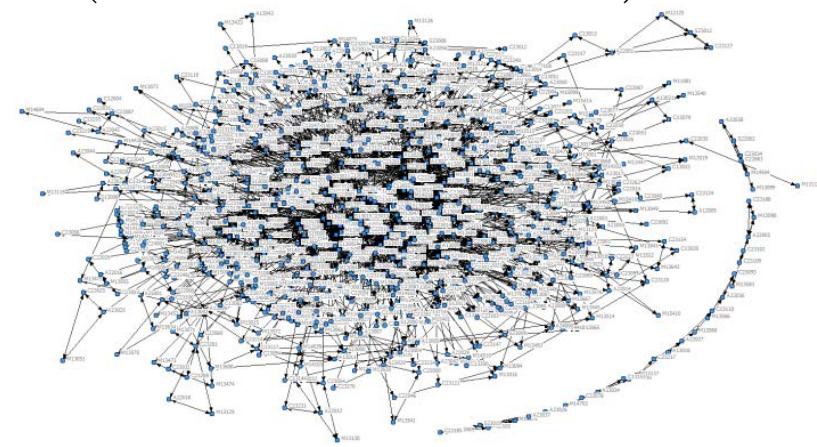

2012 (794 nodes and 5289 connections)

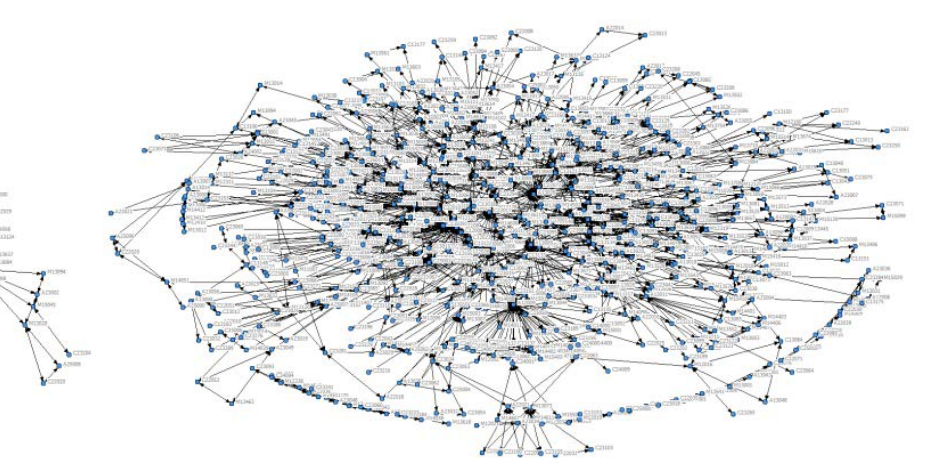

2010 (751 nodes and 3661 connections)

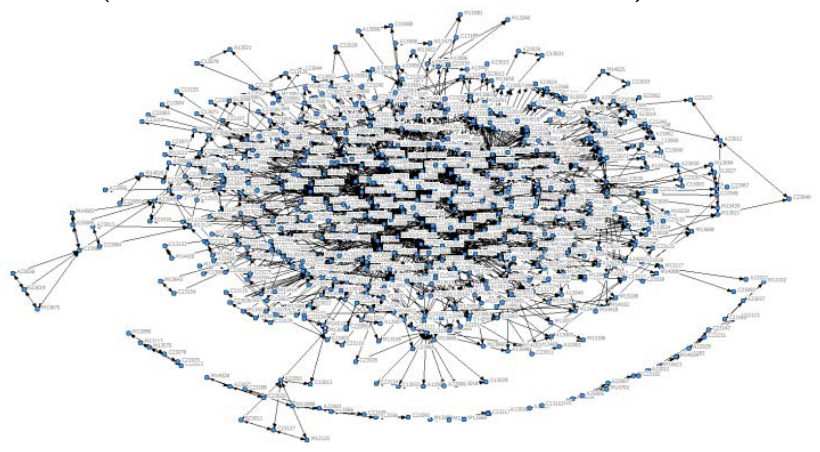

2013 (714 nodes and 4582 connections)

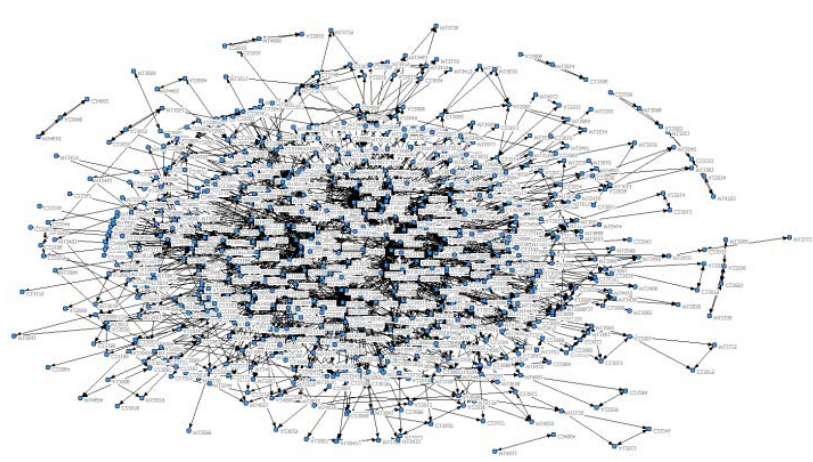

2011 (742 nodes and 5003 connections)

Figure 2: Organizational evolution of PIPs in WNHTDZ 
a) Density

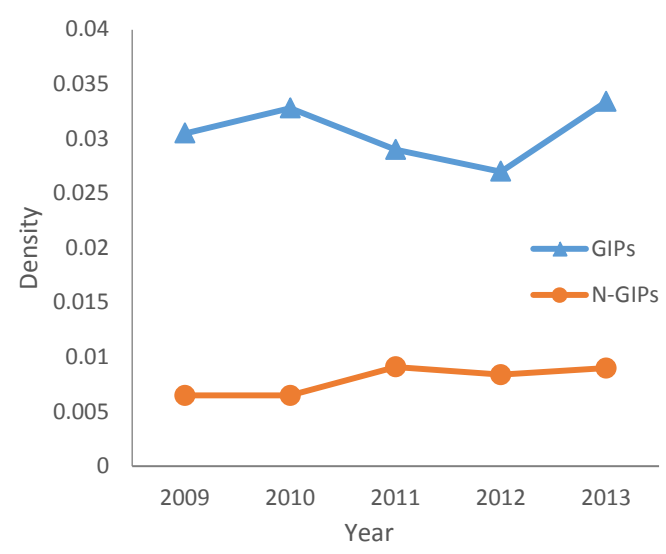

c) Average path length

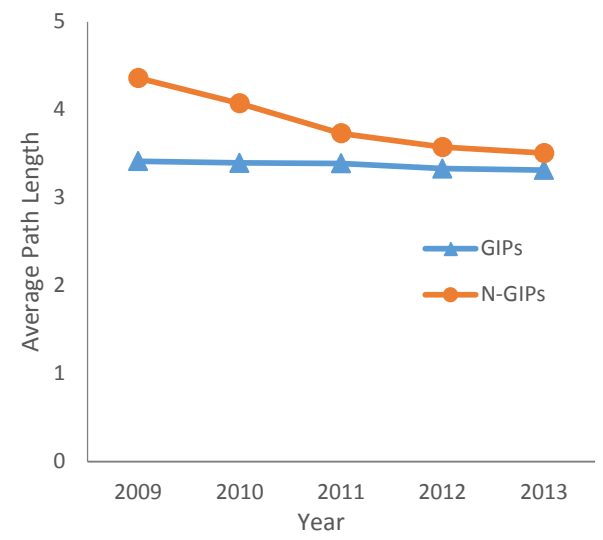

b) Clustering coefficient

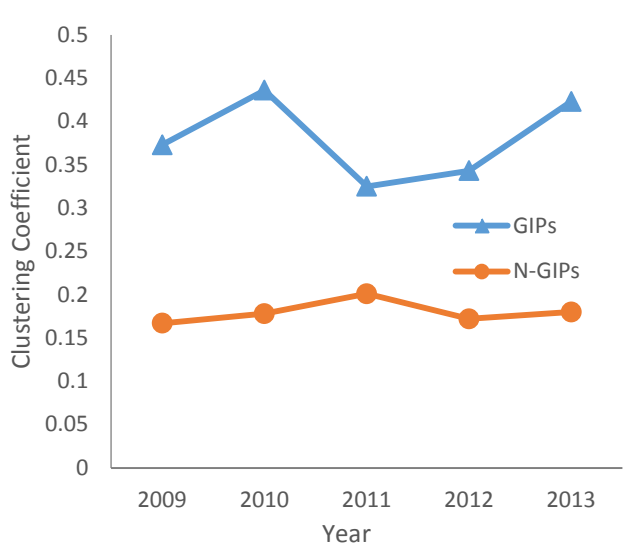

d) The component

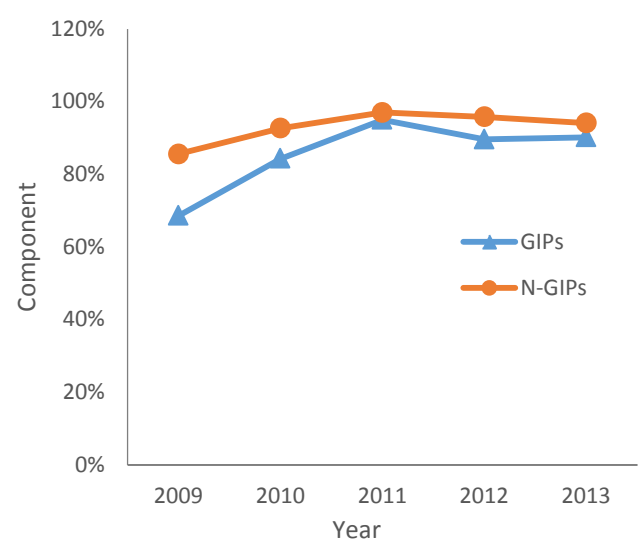

Figure 3: The comparison between GIPs and PIPs a) density, b) clustering coefficient, c) avarage path length, and d) the component

Note: all indexes were standardized to ensure an effective comparison.

\section{Comparative analysis between GIPs and PIPs: individual nodes}

Degree centrality means the number of ties to other nodes that a node contains in the network, which is used to measure the node position in a network. In GIPs, design companies usually have higher degree centrality, while other companies vary widely. For instance, A12004 (notation is referred in Table 4) and A13028 are two main design companies. For PIPs, owners usually have higher degree centrality. Both M11219 and M11016 are main owners and also the most connected position in the network.

Closeness centrality measures the ability of a node to be influenced or controlled by others. In GIPs, the trend is quite stable in which an owner (with M11219 based), a design company (A13039) and a construction company (C23174) normally top the list. They are also the key players who bridge the connections among different clusters. For PIPs, the top three companies vary randomly. 
Table 4: Selected nodes ranked as top 3 for degree centrality and closeness centrality

\begin{tabular}{|c|c|c|c|c|c|c|c|}
\hline & & 2009 & 2010 & 2011 & 2012 & 2013 & $\begin{array}{l}\text { High frequent } \\
\text { nodes* }\end{array}$ \\
\hline \multirow{6}{*}{$\begin{array}{l}\text { Degree } \\
\text { centrality }\end{array}$} & \multirow{3}{*}{$\begin{array}{l}\text { Top } 3 \text { nodes } \\
\text { for GIP } \\
\text { network }\end{array}$} & A12004 & M12108 & M12108 & A12004 & S13005 & A12004 (3) \\
\hline & & A13031 & A12004 & A12006 & A13039 & A13009 & A13028 (3) \\
\hline & & A12009 & A12006 & A13028 & A13028 & A13028 & \\
\hline & \multirow{3}{*}{$\begin{array}{l}\text { Top } 3 \text { nodes } \\
\text { for PIP } \\
\text { network }\end{array}$} & A13039 & A13039 & A13039 & M11016 & M12108 & A13039 (4) \\
\hline & & M11219 & M11219 & M11016 & A13039 & M11016 & M11219 (5) \\
\hline & & M11013 & M11016 & M11219 & M11219 & M11219 & M11016 (4) \\
\hline \multirow{6}{*}{$\begin{array}{l}\text { Closeness } \\
\text { centrality }\end{array}$} & \multirow{3}{*}{$\begin{array}{l}\text { Top } 3 \text { nodes } \\
\text { for GIP } \\
\text { network }\end{array}$} & A13039 & A13039 & A13039 & C23174 & C23174 & A13039 (5) \\
\hline & & M11013 & $\mathrm{C} 23174$ & C23174 & A13039 & A13039 & C23174 (5) \\
\hline & & C23174 & M11219 & M11219 & M11219 & M11219 & M11219 (4) \\
\hline & \multirow{3}{*}{$\begin{array}{l}\text { Top } 3 \text { nodes } \\
\text { for } \quad \text { PIP } \\
\text { network }\end{array}$} & M12126 & A12004 & M12108 & M12108 & S13005 & A12004 (3) \\
\hline & & A12004 & C22017 & M12126 & S13005 & A13028 & M12108 (3) \\
\hline & & C22017 & M12108 & C13026 & A12004 & A13009 & \\
\hline
\end{tabular}

*Note: High frequent nodes are explained in full name as follows. Wuxi Institute of Architectural Design Co. Ltd. (A12004); Wuxi Light Industry Design and Research Institute Co., Ltd. (A13028); Wuxi New District Wangzhuang Street Office (M11219); River Creek street Office (M11016); Wuxi civil design Co. (A13039)

\section{Governance Strategies}

\section{Organizational evolution}

The evolutionary trend of organization network can be summarized as follows. First, GIPs network has more intense connections and smaller networks than PIPs network, indicating companies within GIPs network are more convenient to collaborate. Such high connection is mainly related to the government investment principles, management modes, and tendering system. Most GIPs were likely to be performed or supported by state-owned enterprise. So the owners of GIPs can have higher chance to continually work with past partners who also hope to obtain more projects. And the owners of PIPs are relatively dispersed across different fields, and many owners only have one project or one time investment, therefore the PIPs market is stable and its level of collaboration is low.

Second, the evolution of the network indicates that for both GIPs and PIPs networks, 1) the collaboration closeness increased, and 2) the distance between companies decreased over time. This trend is more apparent for GIPs than PIPs, because government evaluated the post-project performance and set tendering priority to those good performers for future projects. This strengthens the relationship within the collaboration network.

However, GIPs network shows more variances and fluctuations than PIPs network in terms of the value for density, clustering coefficient and component (see figure 3). This may due to the government procurement methods which use open tendering and lowest bid win principles. As a result, the lowest bidder may change for different projects. Such procurement policy may hinder the long-term collaborative partnerships. 


\section{Coping strategies}

Effective project governance is the key to project success (Klakegg, 2009). The purpose of project network governance is to help improve the project performance and stabilize the whole network. Procurement policy and contractual arrangements play an important role in project network governance, especially when governing a large project and its supply chain (Brady et al., 2006). Olsen et al. (2005) stated that a governance structure should consist of multiple mechanisms such as contractual incentives, the use of contracts, relational norms, and administrative controls, in order to handle complex procurements for various stakeholders. The governance structure of a project encompasses the management of relationships among various project stakeholders (Artto, Eloranta and Kujala, 2008). In addition, a project contract is also intended to create a cooperative organization, where participating workers are motivated to work towards shared goals (Turner and Simister, 2001).

In order to manage GIPs collaboration network effectively, well-designed policies such as procurement policy or contractual arrangement are needed. For PIPs, market-based policies with more incentive for collaborative mechanisms are needed, such as efficient market disciplines and tendering mechanisms.

Based on the above organizational evolution, this study proposes several strategies to help govern the megaproject organization in a more efficient and reliable manner. Overall, managing GIPs collaboration network is essential to the success of the whole network. The closeness of collaboration in GIPs network needs well-designed policies, such as procurement policy or contractual arrangement, to guide companies building long-term collaboration, and also to help improve the performance of public project management. However, special focus should be given to the collaboration of the small cluster. Intimate relationships in a small cluster will lead to unfair competition, corruption, and eventually poor project performance. For instance, architecture and design firms are well connected to all other nodes, therefore it is vital to reconsider the governance mechanisms in order to monitor and to incentivize the influence of designers to the GIPs network.

In addition, the evolution of GIPs network is not as stable as the PIPs network, meaning the management modes, rules, and mechanisms of GIPs might keep changing. Such frequent changes create difficulties for organizational governance. As Provan, Milward and Isett (2002) stated, the core issue of organization network governance is governance mechanisms, including commitments and contracts. Therefore, future management mode should be improved and relevant policies redesigned to stabilize the long-term collaborative network and strengthen the control. Powell (2003) suggested three ways of improving the governance of network organization including trust, learning and innovation. The future policy for this case could focus on 1) building the knowledge base of successful governance mechanisms, and 2) selecting and diffusing the effective governance mechanism in order to stabilize the collaborative networking features, and eventually to make the project network more controlled.

The network character of PIPs is more stable than GIPs, and this suggests that the related market mechanism is relatively mature. Such a stable trend also reflects the success of previous policies by concentrating on market-based governance rather than project-based governance. Future policies can rely on market-based policies with more incentive for collaborative mechanisms, such as establishing efficient market disciplines, equitable legal system with mutually-supported guidance, efficient tendering mechanisms, and so on (Bresnen et al., 2003; Flyvbjerg, 2007). Meanwhile, owners located in core places within the PIPs network, and the management of owners' behaviours should be highly monitored. 


\section{Conclusion}

This paper investigates the characteristics of the evolution of megaprojects organization in China by using SNA, comparing the organizational evolution of GIPs and PIPs networks, then proposing corresponding governance policies for both GIPs and PIPs. The key conclusion is as follows.

The organization network of GIPs has higher closeness than PIPs, and therefore companies in GIPs have easier and better chances to collaborate with others. However, the network of GIPs fluctuated over time and required more stabilized governance polices. The collaboration network of PIPs has lower closeness, as private owners managed relatively small numbers of projects. The network character of PIPs is stable due to relatively matured market mechanisms. Therefore future policy will encourage more collaboration among the companies in the PIPs network.

This research contributes to the body of knowledge by expanding the current research on the megaproject organizations from static evaluation to long-term evolutionary analysis, offering effective governance mechanisms for organizational dynamic evolution in different phases, and comparing various governance strategies for megaproject organizations. Although this study selected a typical case in Wuxi, the discussion and conclusion from this study could potentially contribute to understanding the governance of construction projects in other national development zones.

However, several limitations exist in this research. First, the study only analyzes the overall characteristics of whole megaprojects organization network, but does not investigate the individual node and its influence in the network. Therefore future research can build a more holistic network to include both whole network analysis and individual node analysis. Second, this study focuses more on the performance of the organizational network, but hasn't considered the performance of megaproject, such as the project quality, cost and schedule. Therefore, further study can establish the linkage between organization network and project performance in order to better understand the megaproject evolution.

\section{Acknowledgment}

This study is supported by the National Natural Science Foundation of China (project numbers: 71390523 and 71471136). The views represented in this article are those of the individual authors only.

\section{Reference}

Artto, K., Eloranta, K. and Kujala, J., 2008. Subcontractors' business relationships as risk sources in project networks. International Journal of managing projects in business, 1(1), pp.88-105.

Baker, W.E., 2000. Achieving success through social capital: Tapping the bidden resources in your personal and business networks. San Francisco, CA: Jossey-Bass.

Borgatti, S.P. and Foster, P.C., 2003. The network paradigm in organizational research: A review and typology. Journal of management, 29(6), pp.991-1013. doi: http://dx.doi.org/10.1016/S0149-206303 00087-4

Borgatti, S.P. and Halgin, D.S., 2011. On network theory. Organization Science, 22(5), pp.1168-81. doi: http://dx.doi.org/10.1287/orsc.1100.0641

Brady, T., Davies, A., Gann, D. and Rush, H., 2006. Learning to manage mega projects: the case of BAA and Heathrow Terminal 5. In: IRNOP VII Project Research Conference. Xi'an, China, 11-13 Oct 2006.

Bresnen, M., Edelman, L., Newell, S., Scarbrough, H. and Swan, J., 2003. Social Practices and the Management of Knowledge in Project Environments. International journal of project management, 21(3), pp.157-66. doi: http://dx.doi.org/10.1016/S0263-7863(02)00090-X

Burt, R.S., 2004. Structural Holes and Good Ideas. American journal of sociology, 110(2), pp.349-99. doi: http://dx.doi.org/10.1086/421787 
Buzzell, R.D. and Gale, B.T., 1987. The PIMS principles: Linking strategy to performance. New York: Simon and Schuster Inc.

Chen, S.-J.G., 2005. An integrated methodological framework for project task coordination and team organization in concurrent engineering. Concurrent Engineering, 13(3), pp.185-97. doi: http://dx.doi.org/10.1177/1063293X05056462

Chinowsky, P. and Taylor, J.E., 2012. Networks in engineering: an emerging approach to project organization studies. Engineering Project Organization Journal, 2(1-2), pp.15-26. doi: http://dx.doi.org/10.1080/21573727.2011.635647

Chinowsky, P.S., Diekmann, J. and O’Brien, J., 2009. Project organizations as social networks. Journal of Construction Engineering and Management, 136(4), pp.452-8. doi: http://dx.doi.org/10.1061/(ASCE)CO.1943-7862.0000161

Doreian, P., Batagelj, V. and Ferligoj, A., 2004. Generalized blockmodeling of two-mode network data. Social networks, 26(1), pp.29-53. doi: http://dx.doi.org/10.1016/j.socnet.2004.01.002

Dubois, A. and Gadde, L.-E., 2000. Supply strategy and network effects-purchasing behaviour in the construction industry. European Journal of Purchasing \& Supply Management, 6(3), pp.207-15. doi: http://dx.doi.org/10.1016/S0969-7012(00)00016-2

Flyvbjerg, B., 2007. Megaproject Policy and Planning: Problems, Causes, Cures. Summary of Dissertation for Higher Doctorate in Science,(Dr. Scient.), Aalborg: Aalborg University.

Gordon, A.F., 2008. Ghostly matters: Haunting and the sociological imagination: University of Minnesota Press.

Gray, R.J., 2001. Organisational climate and project success. International journal of project management, 19(2), pp.103-9. doi: http://dx.doi.org/10.1016/S0263-7863(99)00060-5

Jeffrey, P. and Salancik, G.R., 1978. The External Control of Organizations. New York: Harper \& Row.

Jones, C., Hesterly, W.S. and Borgatti, S.P., 1997. A general theory of network governance: Exchange conditions and social mechanisms. Academy of management review, 22(4), pp.911-45. doi: http://dx.doi.org/10.2307/259249 and http://dx.doi.org/10.5465/AMR.1997.9711022109

Jones, H.A.C., Noble, C., Damsgård, B. and Pearce, G.P., 2011. Social network analysis of the behavioural interactions that influence the development of fin damage in Atlantic salmon parr (Salmo salar) held at different stocking densities. Applied Animal Behaviour Science, 133(1), pp.117-26. doi: http://dx.doi.org/10.1016/j.applanim.2011.05.005

Kilduff, M. and Tsai, W., 2003. Social networks and organizations. London: Sage Publications.

Klakegg, O.J., 2009. Pursuing relevance and sustainability: Improvement strategies for major public projects. International Journal of managing projects in business, 2(4), pp.499-518.

Li, Y., Lu, Y., Kwak, Y.H., Le, Y. and He, Q., 2011. Social network analysis and organizational control in complex projects: construction of EXPO 2010 in China. Engineering Project Organization Journal, 1(4), pp.223-37. doi: http://dx.doi.org/10.1080/21573727.2011.601453

Li, Y., Lu, Y., Li, D. and Ma, L., 2015. Metanetwork Analysis for Project Task Assignment. Journal of Construction Engineering and Management. In press. doi: http://dx.doi.org/10.1061/(ASCE)CO.1943-7862.0001019

Liu, L., Han, C. and Xu, W., 2014. Evolutionary analysis of the collaboration networks within National Quality Award Projects of China. International journal of project management, 33(3), pp.599-609. doi: http://dx.doi.org/10.1016/j.ijproman.2014.11.003

Loraine, R.K., 1994. Project specific partnering. Engineering, Construction and Architectural Management, 1(1), pp.5-16. doi: http://dx.doi.org/10.1108/eb020989

Miller, R. and Hobbs, J.B., 2005. Governance regimes for large complex projects. Project Management Journal, 36(3), pp.42-50.

Newman, M.E., 2003. The structure and function of complex networks. SLAM review, 45(2), pp.167-256. doi: http://dx.doi.org/10.1137/S003614450342480

Obstfeld, D., 2005. Social networks, the tertius iungens orientation, and involvement in innovation. Administrative science quarterly, 50(1), pp.100-30.

Olsen, B.E., Haugland, S.A., Karlsen, E. and Husøy, G.J., 2005. Governance of complex procurements in the oil and gas industry. Journal of Purchasing and Supply management, 11(1), pp.1-13. doi: http://dx.doi.org/10.1016/i.pursup.2005.03.003

Powell, W., 2003. Neither Market nor Hierarchy: Network Forms of Organization. In: Michael J Handel ed. The sociology of organizations: classic, contemporary, and critical readings. Thousand Oaks, CA: Sage Publications. pp.315-30.

Provan, K.G., Milward, H.B. and Isett, K.R., 2002. Collaboration and integration of community-based health and human services in a nonprofit managed care system. Health care management review, 27(1), pp.21-32. doi: http://dx.doi.org/10.1097/00004010-200201000-00003

Pryke, S.D., 2005. Towards a social network theory of project governance. Construction Management and Economics, 23(9), pp.927-39. doi: http://dx.doi.org/10.1080/01446190500184196

Quinn, D., Chen, L. and Mulvenna, M., 2012. Social Network Analysis. International Journal of Ambient Computing and Intelligence, 4(3), pp.46-58. doi: http://dx.doi.org/10.4018/jaci.2012070104

Scott, J. and Carrington, P.J., 2011. The SAGE handbook of social network analysis. London: SAGE Publications.

Sparrowe, R.T., Liden, R.C., Wayne, S.J. and Kraimer, M.L., 2001. Social networks and the performance of individuals and groups. Academy of management journal, 44(2), pp.316-25. doi: http://dx.doi.org/10.2307/3069458 
Szyliowicz, J.S. and Goetz, A.R., 1995. Getting realistic about megaproject planning: The case of the new Denver International Airport. Policy Sciences, 28(4), pp.347-67. doi: http://dx.doi.org/10.1007/BF01000249

Thiry, M. and Deguire, M., 2007. Recent developments in project-based organisations. International journal of project management, 25(7), pp.649-58. doi: http://dx.doi.org/10.1016/j.ijproman.2007.02.001

Turner, J.R. and Simister, S.J., 2001. Project contract management and a theory of organization. International journal of project management, 19(8), pp.457-64. doi: http://dx.doi.org/10.1016/S0263-7863(01)00051-5

Wasserman, S., 1994. Social network analysis: Methods and applications: Cambridge University Press. doi: http://dx.doi.org/10.1017/CBO9780511815478

Winch, G., 1989. The construction firm and the construction project: a transaction cost approach. Construction Management and Economics, 7(4), pp.331-45. doi: http://dx.doi.org/10.1080/01446198900000032 